Etnográfica

Revista do Centro em Rede de Investigação em

Antropologia

vol. $14(3) \mid 2010$

Vol. 14 (3)

\title{
"Somos todos marítimos": uma etnografia das (in)visibilidades do poder na representação social do passado local em Ílhavo
}

"We're all seafarers": an ethnography of the (in)visibilities of power in the social representation of the local past in Ílhavo

\section{Elsa Peralta}

\section{OpenEdition}

Journals

Edição electrónica

URL: https://journals.openedition.org/etnografica/249

DOI: $10.4000 /$ etnografica.249

ISSN: 2182-2891

Editora

Centro em Rede de Investigação em Antropologia

Edição impressa

Data de publição: 1 outubro 2010

Paginação: 443-464

ISSN: 0873-6561

Refêrencia eletrónica

Elsa Peralta, «"Somos todos marítimos": uma etnografia das (in)visibilidades do poder na representação social do passado local em Ílhavo», Etnográfica [Online], vol. 14 (3) | 2010, posto online no dia 21 outubro 2011, consultado o 11 fevereiro 2022. URL: http://journals.openedition.org/ etnografica/249 ; DOI: https://doi.org/10.4000/etnografica.249

\section{(c) (†) 8}

Etnográfica is licensed under a Creative Commons Attribution-NonCommercial 4.0 International License. 


\title{
"Somos todos marítimos": uma etnografia das (in)visibilidades do poder na representação social do passado local em Ílhavo
}

\section{Elsa Peralta}

\begin{abstract}
Tendo como base empírica o processo de construção de uma "memória do mar" em Ílhavo, com especial incidência sobre a pesca do bacalhau à linha, pretende-se discutir a forma como as noções de identidade e de pertença são construídas por recurso à fixação de imagens selectivas de um passado que é activado de acordo com as agendas de poder de determinados grupos. No caso em análise, a identidade local é articulada por uma narrativa de evocação marítima que reproduz a identidade de classe detida por aqueles que ocupavam posições hierárquicas dominantes na prática da actividade agora representada. Tornando o "seu" passado ostensivamente visível, estes grupos conferem invisibilidade às profundas assimetrias presentes na prática da actividade da qual se reclamam os protagonistas.
\end{abstract}

PALAVRAS-CHAVE: memória, identidade, classe, poder, visibilidade, Ílhavo.

EM 1925 MAURICE HALBWACHS INTRODUZIU FORMALMENTE O CONCEITO de memória colectiva no léxico das ciências sociais. Segundo Halbwachs, o passado é uma construção social moldada pelos interesses, pelas aspirações, pelas ansiedades manifestadas em cada momento histórico. Como refere no prefácio de Les cadres sociaux de la mémoire: "Os quadros colectivos são [...] os instrumentos utilizados pela memória colectiva para reconstruir uma imagem do passado em concordância, em cada época, com as ideias dominantes da sociedade" (Halbwachs 1992 [1925]: 40 - tradução minha). As "ideias" que temos em relação ao passado, os juízos que fazemos sobre acontecimentos pretéritos e, inclusivamente, os aspectos ou ângulos do passado que decidimos colectivamente deter e transmitir para o futuro são profundamente contingentes com as condições presentes a partir das quais a recordação colectiva 
se articula. À medida que as condições presentes mudam, também mudam as interpretações do passado.

O passado, quando articulado pela memória tem, portanto, pouco valor intrínseco; o seu valor depende antes dos significados que lhe são atribuídos pelo presente (ou por sucessivos presentes) como reflexo de um conjunto de relações sociais e de posições de poder observáveis num determinado contexto histórico. A memória, tanto colectiva como individual, é sempre selectiva, envolvendo tanto de recordação quanto de esquecimento. Esta selecção de elementos do passado, que nuns casos se faz deliberada e noutros inadvertidamente, cumpre geralmente propósitos instrumentais e procura satisfazer as necessidades representacionais de grupos específicos. Por via da activação de determinadas versões do passado ou por via da subversão de anteriores versões dominantes, estes grupos asseveram ou reforçam o seu respectivo posicionamento simbólico numa escala de valorizações sociais grupais. A memória detém, portanto, um valor instrumental ao serviço do incremento de um "poder táctico", tal como conceptualizado por Eric Wolf, ou seja, "o poder que controla os cenários nos quais as pessoas podem exibir as suas potencialidades" (Wolf 2001: 384 - tradução minha) e, assim, adquirir vantagem sobre outros ou controlar a sua acção.

Os aspectos do passado que são recordados e a forma como são recordados revelam, portanto, questões importantes acerca do poder, pois as representações do passado comportam consigo a evidência de quem detém os capitais (económico, social, cultural) necessários para assegurar uma posição dominante num determinado contexto social. Como refere Richard Terdiman, "A memória é o mecanismo pelo qual a ideologia se materializa" (1993: 33 - tradução minha), validando as narrativas dos grupos ou das culturas dominantes, e suportando e consolidando as desigualdades (pre)existentes num determinado tecido social. É comum que o desenvolvimento de uma determinada memória pública, através de museus, de memoriais, da paisagem construída ou de comemorações, envolva o nivelamento das desigualdades existentes no seio de um determinado grupo ou o naturalizar das tensões que tais desigualdades geraram. A história contada pela memória é uma história linear e harmónica, pois da sua coerência, conseguida mediante a exclusão ou omissão de aspectos perturbadores, depende a sua força como motor de coesão grupal. É a partir desta coerência que os grupos desenham uma "imagem de continuidade" sobre o seu percurso no tempo (Connerton 1989: 12).

A memória, ao tornar-se pública, arrasta consigo um conjunto de significados associados que correspondem às visões do mundo, aos objectivos e às necessidades dos grupos que detêm o poder suficiente para activar uma determinada versão da história. Quando assim é, a cultura material seleccionada e/ou erigida para testemunhar a fiabilidade da memória é convertida em objectos sagrados aos quais os envolvidos, mesmo aqueles cujas "histórias" foram 
omitidas, são chamados a prestar culto, fornecendo uma validação colectiva à narrativa dominante. A sua importância na estruturação das relações de poder e nas hierarquias e sistemas de classificação dominantes resulta de uma ponderação subtil dos termos do binómio visibilidade/invisibilidade dos significados veiculados por estes objectos de culto. Ao serem inseridos na esfera pública, os objectos do passado tornam-se visíveis. Convertem-se, bem como os significados neles implícitos, em "focos da atenção colectiva" (Dayan 2005: 55 - tradução minha). Dito de outro modo, atestam a "eficácia mobilizacional da posição cultural central" (Turner 1975: 146 - tradução minha) ocupada pelos grupos que, em cada momento, detêm o poder dominante no seio de determinado grupo ou sociedade. Esta condição faz com que visões alternativas do curso da história sejam automaticamente secundarizadas devido à sua natureza não pública, ou seja, à sua invisibilidade. Por outro lado, as narrativas de dominação e as relações de poder perpetuadas pelos actos e pelos objectos da memória são tornadas invisíveis pela linearidade, pela coerência e pela harmonia do passado representado.

As representações do passado na esfera pública reflectem, portanto, sempre as relações de poder presentes num determinado contexto histórico e traduzem a tentativa de determinados grupos de se apropriarem estrategicamente de um espaço representacional privilegiado relativamente aos demais grupos presentes no tecido social. Não quer isto dizer que os discursos sobre o passado sejam fixos ou que os agentes da sua representação sejam inalteráveis. O carácter dinâmico e conflitual da memória faz com que as versões do passado sejam sempre provisórias e contingentes com as condições de cada presente. Neste sentido, as questões de quem selecciona o passado, com que razões e em benefício de quem, apresentam-se como fundamentais para uma leitura do passado conforme é formulado por cada presente. São estas as principais questões colocadas no estudo de caso tratado neste artigo, que incide sobre os processos de activação de uma memória pública observados em Ílhavo.

\section{O CONTEXTO DA MEMÓRIA}

Sendo constituído por apenas quatro freguesias, ${ }^{1}$ o concelho de Ílhavo é, porém, um concelho muito heterogéneo. Essa heterogeneidade deve ser explicada, antes de mais, pela localização do concelho na região litoral centro-norte de Portugal, uma região que se consolidou, a partir de meados da década de 1970, como um espaço industrial, sob a égide do centro comercial e industrial que a cidade do Porto representa (Reis 1993).

I As quatro freguesias são a Gafanha da Nazaré, a Gafanha da Encarnação, a Gafanha do Carmo e São Salvador, correspondendo esta última à sede do concelho, elevada à categoria de cidade em 1990. 
Situando-se na faixa litoral do país, participando das dinâmicas associadas à sua localização geográfica, usufruindo de bons eixos viários, e inserindo-se numa aglomeração urbana alargada, ${ }^{2}$ já que é contíguo ao concelho de Aveiro, o que lhe permite beneficiar do factor de polarização exercido por dois equipamentos públicos de elevado potencial de expansão - a Universidade de Aveiro e o Porto de Aveiro -, Ílhavo evidencia dinâmicas de crescimento urbano e processos de diferenciação socioespacial que são próprios das cidades médias. Com efeito, em 2001 residiam no concelho de Ílhavo 37.209 indivíduos, tendo-se registado um crescimento populacional muito elevado no período de uma década, bastante superior ao registado no país. ${ }^{3}$ Trata-se de variações muito positivas, que inverteram as perdas populacionais da década de 1960 , devidas à emigração, reflectindo as migrações do interior para o litoral do país e as tendências de crescimento demográfico em toda a região, mas também o carácter periférico de Ílhavo face ao centro urbano de Aveiro, o que potenciou as migrações pendulares.

Este crescimento populacional resulta numa pressão considerável sobre o território. Ocupando o concelho uma área de apenas $73,5 \mathrm{~km}^{2}$, a densidade populacional cifra-se em 506 habitantes por $\mathrm{km}^{2}$, o que faz dele o mais densamente povoado da região, registando-se uma significativa tendência de crescimento do parque habitacional, destinado quer ao alojamento familiar, quer ao alojamento de residência sazonal ou secundária, e localizado sobretudo nas zonas balneares do concelho - Costa Nova e Barra.

Inserido numa vasta região lagunar - a ria de Aveiro - e dispondo de uma faixa costeira considerável, historicamente as actividades económicas do concelho eram aquelas ligadas à pesca e à agricultura, num sistema produtivo misto que tirava partido dos recursos do mar e da ria, complementado com explorações agrícolas de carácter familiar e com outras actividades de natureza industrial, como a construção naval, a marinha mercante e a exploração salina. A indústria cerâmica tem também uma implantação antiga no concelho, desde a criação da fábrica de cerâmica da Vista Alegre em 1824.

Nas Gafanhas desenvolve-se um sistema produtivo misto, que tira partido dos recursos do mar e da ria e que se complementa com a actividade agrícola. Nas povoações de Ílhavo e da Costa Nova, há uma dedicação mais exclusiva às actividades marítimas, existindo uma hierarquização simbólica do território, que ainda hoje é expressiva e que resulta de uma maior valorização social

2 Traduzindo as importantes relações funcionais que existem entre os vários territórios que fazem parte do distrito de Aveiro, foi criada, em 2004, a Grande Área Metropolitana de Aveiro (GAMA), que abrange 12 dos 19 municípios do distrito, correspondendo a um universo de cerca de 400 mil habitantes.

3 Entre 1991 e 2001, o concelho de Ílhavo registou uma taxa de crescimento populacional de 12\%, enquanto que a média registada para o país se cifrou em 5\%, e em $10 \%$ para o conjunto dos concelhos que fazem parte do distrito de Aveiro (segundo os censos de 1991 e de 2001). 
daqueles que eram exclusivamente marítimos, não sendo, por isso, de espantar que o elemento mais marcante da identidade local seja a percepção de uma relação privilegiada com o mar.

Os primeiros pescadores da zona terão sido os da arte da xávega que, na época própria, saíam para a pesca da sardinha, guardando durante o resto do ano as suas alfaias nos palheiros que se erguiam sobre estacas nos areais do litoral. Mas a actividade piscatória de Ílhavo deve essencialmente a sua singularidade à importância que a pesca do bacalhau adquiriu na localidade, sobretudo entre os anos 30 e 70 do século XX, os anos da "Campanha do Bacalhau" do Estado Novo. O fim da protecção do Estado ao sector, em 1974, mas também a sobrepesca do bacalhau e a crise dos stocks, que resultaram na imposição de medidas radicais em termos de redução das capturas, fazem com que o sector entre em ruptura. Como resultado, do final da década de 1980 até à actualidade Portugal viu a sua quota de pesca do bacalhau reduzida para um décimo e, apesar dos apelos dos armadores, que reclamam um tratamento diferenciado pelo facto de Portugal ser o maior consumidor mundial per capita de bacalhau, o país perdeu quase $70 \%$ da sua capacidade produtiva no sector (Dias et al. 2001). No entanto, e apesar destas dificuldades, o importante sector industrial local da transformação não foi afectado. Em Ílhavo, o abate das embarcações foi compensado com investimentos nos circuitos importadores e na modernização das unidades industriais de transformação do pescado, mantendo a competitividade da indústria local neste sector.

Devido a estas transformaçoes, a estrutura do emprego no concelho tem sofrido uma assinalável e rápida mutação, verificando-se um decrescimento acentuado do emprego no sector primário, um surto, em décadas recentes, do emprego industrial, e uma tendência recente de forte terciarização da economia local. Face a estas tendências, a Câmara Municipal tem procurado assumir-se como um agente da mudança, tomando a questão da qualificação e do desenvolvimento do concelho como sendo de "competência" autárquica. Neste sentido, estabelece como eixo estratégico de desenvolvimento do concelho uma aposta "no terciário superior como motor e sustentáculo duradouro da economia local" (Câmara Municipal de Ílhavo 2002: 7), com especial destaque para os sectores turístico e imobiliário.

\section{O COMPLEXO MNEMÓNICO}

Em Ílhavo, as autodefinições identitárias locais estão fortemente ancoradas numa idealização de um "estilo de vida" diferenciado, associado à vida marítima que, no passado, as populações do concelho levavam. Este modo específico e particular de "ser ilhavense", baseado na sua muito antiga e "autêntica" tradição marítima, espelha o que Balibar e Wallerstein designam "ilusão retrospectiva" (1991: 86 - tradução minha), segundo a qual a sucessão de gerações 
no seio de um território retrospectivamente definido é percepcionada como transmissão de uma "essência" inalterada que toma por designação a de comunidade. Esta definição essencialista do local, enquanto concreta, evidente, não problemática e a-histórica, ainda que baseada numa forte componente vivencial, é tecida no decurso de um "diálogo simbólico" (Whelan 2005: 61 - tradução minha) estabelecido entre os diversos agentes (elites, poderes instituídos, grupos de interesse) presentes no território e os símbolos que os identificam. Deste diálogo travado ao longo do tempo, resulta um complexo mnemónico, contingente e de limites difusos e incertos, que inscreve o discurso sobre a pertença no "tempo da tradição".

Em Ílhavo, a tradição que serve para definir o que é ser ilhavense é, sobretudo, a tradição do mar, sendo muito comum os seus habitantes definirem a localidade, quer em espaços privados quer na esfera pública, como "uma terra maruja”. O próprio slogan institucional de Ílhavo promove-o como o concelho que tem "o mar por tradição". Contudo, a esta representação dominante e aparentemente homogénea subjaz uma grande diversidade de expressões materiais e uma polissemia de sentidos do que se pode entender por "terra maruja”. Não só todo o território é caracterizado por uma grande heterogeneidade, o que evidencia que as actividades nele desenvolvidas não se resumem às marítimas, como também estas mesmas actividades se revelam diversas e fragmentárias.

Esta representação prevalecente consubstancia-se como um complexo de memórias, incorporando um conjunto de elementos dispersos remotamente conectados entre si por uma ligação difusa e arbitrária a uma entidade simbólica que se designa por "mar", muito embora seja claramente discernível uma hierarquia simbólica entre os elementos seleccionados. As actividades da apanha e da pesca local, por exemplo, porque sazonais e não exclusivas, ou seja, acumuláveis com outras actividades como a lavoura (no passado) ou o turismo (hoje), são as que detêm menor valor simbólico. Além disso, estão associadas a uma representação de pobreza e de marginalização social que não é compatível com a imagem prevalecente da comunidade como uma "terra de heróicos marinheiros", como tantas vezes a localidade me foi descrita no decurso da pesquisa. ${ }^{4}$

Do repertório mnemónico da "terra maruja" faz também parte um conjunto de objectos patrimoniais consagrados que acrescentam um sentido de pitoresco à representação prevalecente. É o caso do trabalho das salinas, dos palheiros da Costa Nova com o seu peculiar cromatismo, ou dos barcos moliceiros da ria. Embora não existindo uma ligação coerente entre estas expressões patrimoniais, pois a cada uma delas correspondem actividades concretas

4 A pesquisa que forneceu a base empírica para a elaboração deste artigo foi realizada entre 2003 e 2005 no âmbito de uma investigação de doutoramento. Os resultados obtidos foram posteriormente publicados sob a forma de livro (ver Peralta 2008). 
muito díspares, todas são integradas na narrativa marítima predominante do ser ilhavense como manifestações diferentes de uma única essência: o sal porque é extraído do mar e porque é fundamental para a salga e conservação do pescado; os palheiros porque originalmente serviam de suporte para a actividade da pesca e hoje porque são habitações balneares; os moliceiros porque evidenciam a mestria no que toca à construção naval e às artes de navegação, sendo ostensivamente desvalorizada a complementaridade existente entre as artes de pesca e de navegação da ria e as actividades agrícolas que dependiam do moliço para a fertilização das terras. Embora estas actividades sejam integradas no complexo mnemónico local, a sua ligação difusa ao mar, bem como o facto de serem expressões patrimoniais previamente apropriadas pelo vizinho (e por vezes tido por rival) concelho de Aveiro na sua própria imagética local, fazem com que as mesmas detenham um estatuto simbólico mais ambivalente em Ílhavo.

Ao contrário dos casos anteriores, no topo das hierarquias simbólicas da memória local estão aquelas actividades univocamente ligadas ao mar, que pressupõem uma dedicação exclusiva, e às quais corresponde um estilo de vida próprio, com tempos, espaços e relações sociais claramente diferenciados. A pesca de largo, em especial a pesca do bacalhau, está entre as actividades que detêm maior valor simbólico.

A exclusividade da ocupação, a distância e a ausência que as campanhas de pesca implicam, a dureza da própria actividade, bem como a noção de sacrifício a ela associada são factores que contribuem para a sacralização, quer das actividades em si mesmas consideradas, quer dos seus participantes ou protagonistas. Como me referiu um informante que herdou esta memória dos seus antepassados, o orgulho que se sente "é tanto maior quanto maior foi o sacrifício, a odisseia e a epopeia dos familiares no mar”. Esta representação é sublimada pela ênfase, subtil mas constante, colocada na navegação em detrimento da pesca. O homem de Ílhavo é um navegador, um marinheiro, ou um mareante. Não é um pescador.

A auto-imagem ideal da localidade é, assim, suportada pela evocação de uma memória de tom épico, que identifica Ílhavo como uma terra que tem um percurso histórico ímpar, feito por uma gesta de bravos mareantes. Não é por isso de estranhar que a pesca do bacalhau, sobretudo a pesca do bacalhau à linha, pela sua poética evocativa e pela sua riqueza iconográfica, forneça os motivos definitivos para a exaltação desta memória épica. A dureza das condições em que era praticada, com uma frota de veleiros brancos que largavam nos mares gelados da Terra Nova e da Gronelândia embarcações (dóris) de um só homem que procediam à captura do pescado, confere a esta pesca, apelidada "faina maior", uma aura épica que faz com que adquira um lugar de destaque no imaginário colectivo local. Tendo a actividade da pesca do bacalhau implicado, em Ílhavo, largos contingentes populacionais, a própria população 
reclama para a localidade o estatuto de "terra do bacalhau" ou "capital do bacalhau" em Portugal. ${ }^{5}$

Mas deste complexo mnemónico fazem parte não só estas actividades concretas, mas também um conjunto de possibilidades imagéticas associadas a um estilo de vida próprio e diferenciado, com as suas correspondentes formas de organização social. A memória do mar de Ílhavo não se resume às actividades de pesca e/ou de navegação nas quais se aloja a representação do passado, mas antes se amplia para incluir o que se percepciona serem as visões do mundo, o "carácter", e o "destino", de quem faz a vida no mar. Desta memória intangível faz parte, por exemplo, a estereotipagem de determinadas formas de organização social, tidas como próprias das populações marítimas. É o caso da recorrente identificação de Ílhavo como "terra do matriarcado", assinalando a predominância do papel da mulher na comunidade devido às prolongadas ausências dos homens. ${ }^{6}$

A memória local consubstancia-se, portanto, como um complexo de limites incertos e difusos, ora ancorando-se em actividades concretas que lhe fornecem corporização, ora entranhando-se no tecido social mediante um quadro de valores e de princípios socialmente observados, ora ainda inscrevendo-se no que Rudy Koshar designou Erinnerungslandschaft (2000: 9) para se referir às qualidades mnemónicas presentes nos lugares do quotidiano ou na própria paisagem natural. Este complexo fixa, através de fronteiras simbólicas de contornos flexíveis, os limites da comunidade de pertença.

\section{OS ACTOS DA MEMÓRIA}

Embora estabelecendo uma interacção entre passado e presente, a memória não é o mesmo que o passado; é antes, como refere Andreas Huyssen, um passado "articulado para ser memória" (Huyssen 1995: 3 - tradução minha).

5 Esta pronta identificação de Ílhavo como "terra do bacalhau" foi-nos oferecida nos mais variados contextos de observação etnográfica e pelos mais diversos, e por vezes dissonantes, indivíduos e grupos presentes no terreno de pesquisa, sendo particularmente expressiva nos discursos veiculados pelo poder político local e pelo jornal O Ilhavense durante o período de observação em apreço. Verificou-se também que, por vezes, os residentes em concelhos limítrofes (por exemplo, em Aveiro) utilizam esta identificação para se referirem à especificidade de Ílhavo.

6 Existe a percepção generalizada da importância e da centralidade do papel da mulher na construção da especificidade histórica e cultural da localidade. Esta percepção é fundada na marcada divisão sexual do trabalho que caracteriza as populações que se dedicam a actividades de pesca e é posteriormente idealizada, generalizando-se para toda a "comunidade imaginada", pela mão dos intelectuais e eruditos locais. Objectos de cultura pública, como uma estátua colocada nas imediações do museu de Ílhavo em que uma mulher e um homem são representados conjuntamente, mas em domínios de actuação distintos, consagram e perpetuam esta divisão/complementaridade de papéis de género. Também aqui, membros dos mais diversos grupos, tanto locais como não locais, utilizam prontamente este marcador simbólico como forma de identificação da localidade. 
Este processo de articulação do passado como memória é um processo performativo que depende de uma sucessão de "actos da memória", tal como definidos por Mieke Bal (1999: vii - tradução minha). Sendo a memória uma construção social, este actos sucedem-se no tempo, com cada novo acto a acrescentar-se aos actos que o antecederam. Apesar de rupturas e cortes representacionais, a construção social do passado faz-se sobre as formulações mnemónicas anteriormente activadas, acrescentando-se novos elementos e descartando-se outros. O que muda são, sobretudo, os actores e os que se reclamam, em cada momento, proprietários dessa representação.

Em Ílhavo, o complexo da memória do mar observado começou a ser activado nas primeiras décadas do século XX, quando um conjunto de eruditos locais elege a "tradição do mar" como essencialmente definidora do carácter distintivo da localidade. Com este propósito, foram organizadas conferências, redigidos poemas e publicados artigos de opinião no entretanto fundado jornal O Ilhavense, a voz pública mais activa ao serviço da construção da tradição local, e foi constituída uma colecção museológica com forte ênfase nos temas marítimos. É também deste período a criação do brasão d'armas do concelho de Ílhavo que, por fixar indelevelmente os limites tradição local, é aqui considerado um acto da memória especialmente significativo.

Não dispondo o concelho de insígnias identificativas, a Comissão Executiva da Câmara Municipal de Ílhavo decide criar um brasão d'armas para o concelho no início da década de 20 do século passado. Devido à sua comprovada erudição, solicita a António Gomes da Rocha Madaíl, um distinto membro da elite local, a criação do dito brasão. ${ }^{7}$ A comissão municipal havia demonstrado a intenção de que este brasão fosse o da família dos donatários da Vila de Ílhavo, mas Rocha Madaíl prefere eleger o mar como ícone do concelho. Neste sentido, adoptou uma galera fenícia como símbolo, tendo por base uma tese não comprovada de que os fenícios teriam fundado Ílhavo. Embora ressalvando não existirem evidências seguras que fundamentem esta suposta origem fenícia, Rocha Madaíl considera, porém, existir uma semelhança entre os ditos fenícios e a tradição marítima e mercantil do concelho, suficiente, a seu ver, para justificar a escolha do símbolo. Desta forma, Rocha Madaíl inauguraria uma definição do "ilhavense" enquanto essencialmente marítimo, em detrimento da expressão das demais actividades existentes no concelho, fixando de forma deliberada e intencional o conteúdo de uma tradição do mar. Como referiu: "O brasão d’Ilhavo, é a sua antiquíssima vida marítima, é o próprio mar, e nele

7 Tendo estudado na Universidade de Coimbra, primeiro Direito e depois Filologia Românica, Rocha Madaíl foi 3. ${ }^{\circ}$ oficial do Liceu José Falcão e organizador da sua biblioteca, tendo depois sido nomeado conservador da Biblioteca Geral da Universidade de Coimbra, cargo que também desempenhou no Arquivo do Museu da mesma Universidade, tendo chegado a director da Biblioteca e Arquivo do Distrito de Braga. 
está a sua tradição maior. Porque não havemos, pois, de acolher esta tradição e fixá-la? Fazendo-o, seremos sinceros, e seremos ilhavenses" (Madaíl 1922: 25).

Ao longo dos anos, muitos outros actos públicos da memória se sucederam, todos eles animados por um grupo restrito de eruditos locais, do qual faziam parte médicos, publicistas, professores, intelectuais e artistas, que tomam as expressões do "povo" para estabelecer a sua propriedade sobre a tradição. Foi entretanto criado um museu, instalado num edifício próprio construído de raiz, com destaque para os temas marítimos, embora outras temáticas, como a cerâmica e a pintura sobre motivos locais, fossem também muito valorizadas. De forma a traduzir a ênfase na temática marítima, mas não excluindo a sua vertente local e regional, o novo museu recebe a designação de Museu Marítimo e Regional de Ílhavo.

Mas, a partir da década de 80 do século passado, um conjunto de acontecimentos precipita uma mudança na forma e no conteúdo da representação do passado local. Esta mudança deveu-se à introdução e posterior sublimação de uma nova temática marítima que se acrescenta e se sobrepõe às demais: a pesca do bacalhau. Até este momento, esta modalidade de pesca não dispunha de um espaço representacional próprio na esfera pública local, embora à escala nacional a pesca do bacalhau tivesse sido objecto de um cuidado investimento simbólico, sobretudo durante os anos das "campanhas do bacalhau" do Estado Novo, iniciadas em 1934 com o objectivo de relançar a frota bacalhoeira portuguesa (Garrido 2003). Procurando exercer um controlo absoluto sobre o sistema, ao regular a produção, a importação e os preços deste produto, o Estado corporativo passa a dirigir a acção de armadores, produtores, pessoal de mar e comerciantes. Passa também a ter uma intervenção directa sobre a frota, condicionando as artes e o tipo, dimensão e capacidade dos navios, privilegiando-se claramente a grande tradição de navegação à vela (embora por vezes com motor auxiliar) e a pesca à linha com dóris, embarcações miúdas que se espalhavam à volta do "navio-mãe" e eram ocupadas por um só homem, que procedia à captura artesanal do pescado com uma linha de mão.

A imagem mítica da White Fleet, assim imortalizada pela cor com que os navios portugueses se distinguiam dos demais durante a II Guerra Mundial, bem como a singularidade da pesca à linha com dóris de um só homem, conferem a esta modalidade de pesca, que só foi abandonada depois de 1974, um tom épico frequentemente sublimado pelo aparelho propagandístico do regime. Mediante rituais públicos e comemorações litúrgicas, o Estado Novo converte, assim, a pesca do bacalhau à linha em revivificação da "grandeza marítima" do "povo português", germinando e alimentando "a imagem hiperbólica das gentes do bacalhau como 'marinheiros' e novos cruzados" (Martins 2001: 182-183).

Certamente que este conjunto de sugestões ideológicas e de encenações épicas em torno desta modalidade de pesca ficaria inscrito no imaginário colectivo local. Tanto mais que os pescadores e suas famílias eram 
frequentemente chamados a participar nas liturgias públicas encetadas com vista à glorificação das campanhas de pesca do Estado Novo. É o caso, por exemplo, das bênçãos dos bacalhoeiros que ocorriam em Lisboa entre Abril e Maio de cada ano antes da largada dos navios para mais uma jornada de seis meses nos mares do Canadá e da Gronelândia. ${ }^{8}$ Contudo, até anos recentes, haviam sido raras as expressões públicas celebratórias desta actividade no meio local. Com efeito, sendo o Museu de Ílhavo um dos principais instrumentos de articulação da memória local, este praticamente não concedia um espaço representacional próprio a esta modalidade de pesca. Só quando efectivamente a pesca do bacalhau começa a entrar em ruptura é que a cultura material e as vivências associadas a esta actividade começam a ser objecto de estratégias representacionais. É a partir de então que o mar, em geral, e a pesca do bacalhau, em particular, ganham univocidade no contexto das formulações mnemónicas públicas locais.

Com efeito, o discurso local em torno das grandes fainas do bacalhau apenas se inaugura após a pesca com dóris ter sido abandonada, em 1974, e, mais concretamente, nas vésperas da entrada de Portugal na Comunidade Económica Europeia, quando um conjunto de políticas restritivas precipitaram o declínio da actividade. São organizados colóquios e palestras sobre a pesca do bacalhau à linha, é realizado um documentário intitulado À Glória Desta Faina, são concebidas exposições itinerantes sobre a temática, e é inaugurada uma exposição temporária no museu a ela dedicada. Por fim, a exposição temporária acaba por converter-se em definitiva, tornando-se o eixo temático fundamental do museu. No processo, para ganhar o espaço expositivo necessário no território museológico e identitário local, empurra para as reservas/esquecimento outros elementos identitários antes considerados fundamentais, mas agora tidos por anacrónicos, como é o caso da colecção de porcelanas da Vista Alegre ou da colecção de pintura.

Os principais agentes desta mudança são Francisco Correia Marques, antigo capitão de navios de pesca à linha nos tempos áureos das campanhas do bacalhau; Ana Maria Lopes, professora do ensino preparatório e secundário, proveniente de uma família de capitães e de armadores e, mais tarde, directora do Museu de Ílhavo, sendo responsável por uma alteração substancial na sua linguagem expositiva; e, finalmente, Aníbal Paião, dirigente da Associação de Armadores da Pesca Industrial e administrador da empresa Pascoal \& Filhos, uma empresa com longa tradição na pesca do bacalhau, também ele detentor de um vasto capital geracional associado a actividades

8 De entre o conjunto de encenações épicas e representações ideológicas em torno desta modalidade de pesca, destaca-se a majestosa cerimónia da "bênção dos bacalhoeiros", realizada de 1936 a 1974. Por inícios de Maio, toda a frota de veleiros se reunia para uma espectacular largada frente ao Mosteiro dos Jerónimos, assinalada com uma eucaristia participada pelas gentes do mar e suas famílias e presidida, a partir de 1941, por D. Manuel Trindade Salgueiro, natural de Ílhavo. 
ligadas ao mar. Como admite: "Eu não posso negar de onde venho. Afinal de contas o meu pai era capitão, o meu avô era capitão, todos os meus familiares são capitães e eu tenho a vida que tenho, não é?".

Estes novos actores assumem, então, a propriedade do passado local, afastando progressivamente do palco da memória os seus anteriores protagonistas. Assumem a liderança do Grupo dos Amigos do Museu, uma agremiação constituída para angariar verbas para a sua gestão, e convertem-no em associação, ampliando substancialmente o seu número de sócios e procurando, sobretudo, reunir pessoas ligadas ao mar e chamar os antigos capitães à participação. Remodelam o discurso expositivo do museu, estabelecem parcerias institucionais e lançam projectos para a remodelação do museu local e para a aquisição de antigos navios bacalhoeiros a funcionar como pólos museológicos do núcleo central.

Muitos destes projectos não foram então realizados devido a falta de verbas. A sua posterior concretização seria apenas tornada possível pela intervenção do executivo municipal no domínio da memória local. Em 1997, o engenheiro Ribau Esteves é eleito presidente da Câmara Municipal de Ílhavo com maioria absoluta pelo Partido Social Democrata. A sua acção no domínio da cultura local cedo se revela, ao contrário da dos seus antecessores, bastante enérgica, logo manifestando a intenção de se ocupar dos destinos, quer dos equipamentos culturais do concelho, quer da memória por eles veiculada. Em contrapartida, disponibiliza os meios requeridos por recurso a fundos comunitários, e fornece a moldura institucional necessária para a concretização dos projectos lançados pelo grupo de Paião, Lopes e Marques. A partir de então, a propriedade exclusiva que estes detinham sobre a memória local viria a ter de ser negociada e partilhada.

Como resultado da entrada em cena deste novo actor, verifica-se uma operação de monumentalização da memória local sem precedentes. Desta operação fazem parte a aquisição, através de um contrato de mecenato cultural, do navio arrastão Santo André, a funcionar como pólo do Museu de Ílhavo, a edificação de uma estátua evocativa dos trabalhadores do mar, intitulada Homem do Mar, a ser colocada numa das principais artérias da cidade de Ílhavo, numa praça junto ao museu, e a definitiva remodelação do Museu de Ílhavo.

Em 21 de Outubro de 2001, em pleno período de pré-campanha eleitoral, seria inaugurado o novo museu, com quadro de pessoal próprio e agora definitivamente apelidado Museu Marítimo de Ílhavo, não deixando dúvidas quanto à sua ênfase temática. ${ }^{9}$ A imponência e arrebatadora arquitectura do novo museu,

9 Concretizando a vocação marítima impressa pela sua arquitectura, o actual museu conta com três salas principais de exposição permanente: a "sala da faina maior", a "sala da ria" e a "sala dos mares", dispondo ainda de uma sala de exposições temporárias, de um auditório com 180 lugares, de uma biblioteca sobre temas marítimos, de um centro de documentação sobre a pesca do bacalhau, de uma cafetaria, uma loja, uma sala de reservas, uma zona administrativa e da sala dos Amigos do Museu. 
“muito Expo'98", como me referiu Aníbal Paião, tão destoante das demais edificações que caracterizam a paisagem construída da localidade, não deixam de interpelar quem se lhe depara. Neste mesmo período é também adoptado o slogan promocional para o concelho, "Ílhavo: o mar por tradição", e é alterada a designação do Museu Marítimo e Regional de Ílhavo, que passa a ser o Museu Marítimo de Ílhavo. Estas acções reflectem nitidamente a intenção de se reforçar uma imagem, simbólica e política, diferenciada para o território. Mas, para além disso, reflectem também a intenção de se reclamar a propriedade sobre a paisagem da memória local, designando não a evidência da história, mas antes o processo ideológico subjacente pelo qual a história se tornou evidente.

\section{AS VISIBILIDADES DA MEMÓRIA}

Os actos que instauram o complexo mnemónico local apoiam-se em suportes ou em "lugares" que conferem visibilidade à memória socialmente construída. Esta visibilidade refere-se, como defendido por Jenks (1995), não apenas às expressões materiais da cultura pública, mas também aos significados nelas contidos.

Em Ílhavo, o passado que é tornado visível incide especialmente sobre a "essência" marítima da localidade, convertendo uma determinada visão do passado na história de um "povo", enquanto suporte da identidade ideal da localidade. Este modo vernáculo de representar o passado celebra as realidades vividas, situadas, comuns, das sociabilidades quotidianas, forjando uma representação identitária eminentemente igualitária, na qual todos se podem rever, naturalizando as tensões de classe, as contradições e os conflitos que emergem no tecido social. São os discursos mnemónicos que tornam esta unidade visível, transformando a localidade numa comunidade arquetípica.

A visibilidade concedida à ideia de "povo" é bem marcada em todos os actos da memória que incidem sobre o passado local. Logo aquando das primeiras formulações mnemónicas da década de 20 do século passado, o que era relevado era uma determinada "essência" marítima cujos resíduos, que subsistiam nas práticas comuns do "povo", urgia preservar antes que se perdessem definitivamente. Influenciada pelo Romantismo, esta ideia de "povo" está fortemente associada a um idílio tradicional que resistia ao progresso acelerado que marcava o desenvolvimento das cidades, e cujos saberes e práticas vulgares detinham um valor que tinha de ser diligentemente preservado pela mão de quem nunca tinha sido povo.

Este modo igualitário de representar o passado que toma como base a ideia de "povo" é retomado com a introdução da temática da pesca do bacalhau. Mas é actualizado para enfatizar a ideia de "comunidade ocupacional", que corresponde, na forma como é representada, a uma classe igualitária de diligentes trabalhadores do mar que, independentemente da sua respectiva posição hierárquica a bordo 
dos navios bacalhoeiros, empenham o seu esforço para tirar o bacalhau dos mares. Como me relatou o capitão Francisco Marques, todos, oficiais e pescadores, se sentiam obrigados pela "ânsia de ter o porão cheio até acima". Esta "ânsia" constituía uma fraternidade de homens unidos por uma força de carácter, por um fito preciso, pela fé em Deus, e pelo respeito ao capitão.

A exposição dedicada à "faina maior" no Museu Marítimo de Ílhavo ${ }^{10}$ ilustra bem como esta narrativa igualitarista é estruturada e ficcionada. A mostra organiza-se em vários sectores distintos. Ao centro, exibe-se uma réplica à escala de um navio tradicional da pesca do bacalhau à linha. No convés podem observar-se os dóris, o parque de pesca onde o pescado era preparado antes de ser transferido para o porão da salga, e todos os instrumentos utilizados numa cadeia de operações mecanizada. Permite-se, assim, ao visitante o privilégio de subir a bordo e recriar na sua imaginação o ambiente físico e material desta modalidade de pesca. Longitudinalmente existem dois planos de exposição. Do lado direito da sala são documentados, através de fotografias, os "bota-abaixo" 11 e as largadas dos navios, e são expostos, numa estrutura criada para o efeito, instrumentos de pesca e algumas curiosidades. Do lado esquerdo, o visitante pode observar o que falta ao navio, percorrendo os principais espaços que ficavam sob o convés: a câmara dos oficiais e o camarote do capitão, o porão, os beliches, o rancho e a cozinha. Numa extremidade desta ala, é ainda dedicado um espaço à representação da construção naval, recriando-se um estaleiro de construção do dóri e estando também patente uma maqueta que procura ilustrar uma seca do bacalhau. A mostra é completada com um filme realizado no tempo áureo da pesca do bacalhau à linha, documentando a actividade da pesca em alto mar e em que predominam as imagens de dóris repletos de pescado e de pescadores no decurso da sua actividade.

A "poética" da mostra exibida permite, desta forma, mediar o acesso do visitante ou do espectador ao domínio do invisível e do ausente (o passado), fazendo-o metonimicamente visível (e presente) (Pomian 1990). Para conseguir este efeito, o discurso expositivo articula a memória da pesca do bacalhau à linha em torno da representação material das estruturas físicas implicadas na prática da actividade. A representação do passado privilegiada é, sobretudo, a da exibição do património vivido e vernáculo do "pescador comum", oferecendo, assim, uma base para a recordação colectiva que articula as diferenças culturais e sociais através do ponto de vista de um "estilo de vida" comum (Dicks 2000 - tradução minha), estruturado em torno de uma sobrevalorização do indivíduo, do engenho, da sorte, do trabalho árduo, da sublimação das artes

10 Conforme observada entre 2003 e 2005, altura em que decorreu o trabalho de campo que serve de base a esta pesquisa.

I U Uma ocasião festiva que assinala o lançamento à água de um novo navio bacalhoeiro. 
de navegação em detrimento da pesca, da protecção divina e da saudade, e na articulação entre uma identidade exclusivamente masculina no mar e exclusivamente feminina em terra.

A expressividade desta representação permite relacionar uma identidade marítima detida por um grupo particular com a população local em geral, exprimindo uma auto-representação do ilhavense como uma "comunidade ocupacional" com uma identidade muito própria. Como me referiu um informante local, "de certa maneira, somos todos marítimos".

\section{AS INVISIBILIDADES DA MEMÓRIA}

Os actores e os proprietários da memória detêm um poder que é neutralizado e nivelado pela invisibilidade conferida pela própria visibilidade das formulações mnemónicas que criam. Ou seja, é o carácter ostensivamente visível dos objectos e dos conteúdos do passado que torna invisíveis as estruturas de poder a eles subjacentes. Em Ílhavo, a visibilidade conferida à ideia de "povo" ou de "comunidade igualitária" de marinheiros, não só relega para o esquecimento um conjunto de expressões culturais locais que não se conformam com a representação prevalecente, ou seja, as associadas àquelas actividades que não são actividades marítimas, como também torna invisíveis as estruturas de poder presentes no seio de uma sociedade local profundamente assimétrica e de actividades profissionais fortemente hierarquizadas.

A principal diferenciação que a representação igualitarista dissimula é a que existe entre oficiais e marinheiros, um princípio de diferenciação marcante que traduz as diferentes posições de classe e de estatuto a bordo dos navios. Esta hierarquização é bem patente na mostra, já referida, dedicada à pesca do bacalhau patente no Museu Marítimo de Ílhavo, traduzindo-se na sobre-representação de uma matriz de poder composta pelo navio (que representa o poder do capitão e do armador), pelo estaleiro do dóri (que representa o importante sector da construção naval), e pela seca (que representa toda a indústria de transformação do pescado), enquanto que o pescador solitário é representado como uma figura alegórica, sem que o seu verdadeiro domínio, o dóri, assuma no contexto expositivo a importância que realmente teve.

Com efeito, na mostra patenteada o dóri encontra-se acondicionado no convés do navio, ou seja, em situação de inactividade, sendo difícil para o visitante captar a função que o pescador desempenhava na pesca do bacalhau, ou mesmo apreender a forma como o bacalhau era efectivamente pescado. Por outro lado, o filme mostrado limita a representação do pescador à figura de "trabalhador do mar", feliz por entregar a generosidade que o mar lhe ofereceu à mão diligente do capitão e do seu armador. Além disso, em comparação com a monumentalidade do navio que figura no centro da exposição, as imagens desgastadas e envelhecidas da película, a par da total inexistência de textos de 
sala informativos, tornam difícil a contextualização da importância do papel do pescador na prática da actividade.

Tal como o emudecimento do pescador, a representação dos principais espaços que ficam sob o convés, dispostos sequencialmente na ala esquerda da sala, reflecte bem as fronteiras físicas, sociais e humanas que existiam entre diferentes posições de classe: em primeiro lugar, para quem entra na sala, surgem a câmara dos oficiais e o camarote do capitão, de seguida o porão de salga, e só depois os beliches, o rancho e a cozinha, onde comiam e dormiam os pescadores. A ordenação dos objectos no contexto expositivo reproduz, assim, a hierarquia que existia a bordo, bem como as fronteiras físicas entre os seus espaços. No entanto, embora seja evidente na narrativa patenteada no museu, esta hierarquia é tornada invisível, quer pela ausência de informação capaz de contextualizar a prática da actividade, quer pelo esvaziamento da moldura humana que enquadrava as estruturas físicas exibidas. Desta forma, o passado é mostrado como um todo coerente, que não só incorpora eventuais versões dissonantes num único passado que é apresentado como "natural", como também se expande a toda a comunidade, fixando uma identidade colectiva fortemente condicionada pelas visões detidas por uma classe particular. Esta transposição do universo de referências particular detido por uma classe de capitães para todo o território geográfico é bem patente na frequente identificação de Ílhavo como uma localidade de onde é originária a maior parte dos oficiais da pesca do bacalhau, traduzindo uma hierarquização simbólica dos lugares, das práticas e das pessoas que melhor definem a essência do "ser ilhavense". Como refere Aníbal Paião, "na década de 50 todos os navios da frota eram comandados por gente de Ílhavo. E não eram só capitães. Capitães, mestranças e tal. Curiosamente, o que nunca tivemos foi pescadores. Tivemos sempre gente de formação."

Mas não só o universo de referências do pescador está ausente da representação. Totalmente ausente está também qualquer alusão à forma como a pesca do bacalhau à linha se inseriu no quadro da política de abastecimentos desenvolvida pelo Estado Novo, bem como os contornos ideológicos que envolviam a prática da actividade, optando-se apenas por reproduzir algumas imagens litúrgicas de bênçãos de bacalhoeiros como forma de preservar o elevado misticismo e sentido religioso que comummente se atribui à "comunidade".

Através deste aparato representacional, não só são obliteradas as implicações ideológicas da prática da actividade, como também é iludido o primitivismo do trabalho e a precariedade da vida dura que se levava ao bordo nos tempos da pesca à linha do bacalhau, caracterizada por aspectos como a falta de higiene e de condições mínimas de salubridade a bordo dos navios, a deficiente assistência médica, a precária habitabilidade dos navios, os acidentes, lacerações, feridas e infecções que a tripulação sofria e, sobretudo, a forma como a pesca era realizada, despejando pescadores solitários para um oceano gelado 
capitaneando uma pequena embarcação à vela a partir da qual procediam à captura do bacalhau, um a um, com uma linha de mão e durante longas jornadas de trabalho. Ausentes estão também as constantes tensões a bordo entre os membros da tripulação, recrutados em pequenos aglomerados piscatórios espalhados pelo litoral português e que viam na pesca do bacalhau a oportunidade de obter um rendimento mais certo capaz de compensar os magros ganhos da pesca costeira ou local, ou então de fugirem à tropa, já que embarcarem nos navios da frota bacalhoeira os isentava do serviço militar e da guerra colonial. Oculta-se ainda a tensão surda que se estabelecia entre oficiais e pescadores, resultado do exercício da firme autoridade do capitão e da imposição de ritmos de trabalho árduos, muito embora, com excepção da greve dos bacalhoeiros ocorrida em 1937, não haja notícia de qualquer tipo de sublevação a bordo.

Tudo isto é omisso na esfera pública da representação. No âmbito da memória pública, a pesca do bacalhau é a expressão maior, a idealização, de uma essência marítima que se toma para definir toda uma comunidade. Neste processo, aqueles que ocupavam posições de poder nos tempos da pesca do bacalhau à linha, sobretudo capitães e demais oficiais e armadores, preservam o seu estatuto simbólico no seio da comunidade, ainda que a actividade que lhes conferiu esse estatuto tivesse cessado e, portanto, anulado o seu poder de facto sobre indivíduos e colectivos. Gozando de um elevado prestígio no seio da localidade, pelos rendimentos que auferiam, pela sua capacidade de recrutamento das tripulações e pelo poder que exerciam a bordo das embarcações ou era assinalado por determinadas práticas exclusivas, esta classe procura proteger os valores e asseverar as visões da realidade derivadas da sua experiência dos eventos que protagonizaram.

A apropriação desta memória por parte do executivo municipal, mais interessado em utilizar a imagética associada ao mar, em geral, e à pesca do bacalhau, em particular, ao serviço da capitalização da imagem promocional do concelho e da performance política dos dirigentes autárquicos, viria a contribuir, porém, para uma crescente "banalização" do passado representado. A ânsia do passado, provocada pelo trauma do desaparecimento abrupto da actividade, cede lugar à nostalgia. $\mathrm{O}$ presente fica saturado de imagens do passado, utilizadas para legitimar a acção dos eleitos municipais e enaltecer a sua imagem política, ou para diferenciar o território político, tornando-o atractivo para investidores ou eventuais turistas.

\section{AS DISSIDÊNCIAS DA MEMÓRIA}

Será interessante perguntar como se relacionam os excluídos do passado com a memória dominante. Como referiram Graham, Ashworth e Tunbridge, o passado é "um campo de conflito e tensão social" (2000: 5 - tradução minha), pelo que a memória é sempre inerentemente dissonante, sendo permeável 
a múltiplas interpretações e utilizações, alterando-se à medida que se alteram os poderes e os interesses representacionais. Os que são excluídos, por vezes, procuram subverter a história dominante construindo "contramemórias” (Foucault 1977 - tradução minha). Outras vezes, procuram concessões representacionais por parte da memória dominante, embora não a desafiando abertamente. Ainda noutros casos, versões não conformes com a memória consensual subsistem, se não na esfera pública, no domínio do privado, através do escárnio, do rumor, da maledicência, nutrindo uma resistência anónima, mas activa, às interpretações dominantes (Scott 1990). Estas leituras alternativas são reactivadas em conversas de café, transmitidas geracionalmente através da convivência familiar, ou preservadas em pequenas recordações, objectos banais que testemunham outros passados.

Em Ílhavo, aqueles que são excluídos da memória pública persistem em guardar a sua versão do passado, mas raramente o fazem fora da sua esfera privada de convivência social, parecendo não deter os capitais necessários para construir a sua própria representação. Embora frequentemente discordem da forma como o passado em que participaram é fixado publicamente, a sua contramemória parece restringir-se ao domínio do privado, ainda que neste denunciem abertamente a dureza do passado e escarneçam a classe dos capitães. A invisibilidade pública da sua versão do passado é, portanto, mais o resultado dos atributos da sua própria posição social, que conferem menor poder para representar o passado, do que o resultado da observância de uma versão unívoca da história da pesca do bacalhau. A forma solícita como tantos destes intervenientes se prontificaram a fornecer-me um testemunho sobre o "seu" passado é disso evidência. Um antigo pescador, que fez quarenta viagens ao bacalhau, quando lhe pergunto se gosta de rememorar este passado, diz-me: "Gosto, mas gosto de contar a realidade. Isto não era um mar de rosas, nem de rosas nem de cravos. Aquilo era uma escravidão. Isto é a realidade, eu não estou a inventar nada." Ainda que esta representação não seja tornada expressa na esfera pública, a sua permanência na esfera privada, bem como a consciência da existência de uma versão dos acontecimentos que não é conforme com a versão pública autorizada, consubstancia-se como uma forma de contramemória que poderá, eventualmente, ser publicamente activada.

Mas não só aqueles que detiveram posições subalternas na pesca do bacalhau discordam da representação prevalecente. Também alguns oficiais criticam abertamente a forma como o passado local é articulado. Expressiva a este respeito é a visão detida por um antigo capitão da pesca do bacalhau à linha. Para ele, esta pesca representava um regime escravizante, assente na disponibilidade de mão-de-obra barata, que tirava partido da debilidade socioeconómica em que viviam as populações litorais portuguesas. $\mathrm{Na}$ sua opinião, os homens delas saídos sujeitavam-se a condições de vida a bordo degradantes, ao autoritarismo de alguns capitães, a horas ininterruptas de trabalho, à 
arbitrariedade do sistema de recrutamento, ao jugo dos armadores. Tudo ao serviço de um regime que procurava retirar os maiores dividendos da actividade ao menor custo. Como refere:

Eu responsabilizo o Salazar pelo fomento da pesca escravizante, antieconómica e desumana que era a pesca do bacalhau à linha. Responsabilizo não só o Salazar mas também os ideólogos do corporativismo, que resulta da Constituição de 1933. E a alma danada da corporação das pescas foi o Pedro Teotónio Pereira, foi um dos responsáveis, um dos grandes ideólogos do corporativismo.

Embora estas visões dissonantes não sejam incorporadas nas visões autorizadas sobre o passado local, e por isso se desvaneçam nos enlevos da transmissão oral, elas fornecem, não obstante, um reservatório de memórias passível de ser activado caso novas condições contextuais façam justificar uma revisão da forma como o passado local é tornado público. O aberto criticismo que é dirigido pelos pescadores à classe dos capitães e a denúncia da precariedade das condições de trabalho e de vida nos tempos da pesca do bacalhau à linha são já evidências da forma como a recordação colectiva se articula em torno de uma mnemónica clara e coerente, neste caso, o antagonismo entre pescadores e capitães. O passado é um campo de batalha entre diferentes visões dos acontecimentos pretéritos que se embatem e renegoceiam com o objectivo de redefinir as posições de influência na hierarquia social. É, neste sentido, sempre uma circuito dialógico entre dominação e resistência.

\section{CONCLUSÃO}

A visibilidade da memória depende de um processo de metonimização do passado, mediante o qual apenas uma parte dos eventos pretéritos são seleccionados para representar o todo que, sem as contradições da realidade vivida, se apresenta de forma coerente e estável. A natureza selectiva da memória é intrínseca à forma como o significado é produzido, articulado e negociado no contexto da experiência quotidiana de atribuição de valor a determinadas categorias em detrimento de outras. Esta experiência é altamente contingente, variando conforme as ansiedades de cada presente, e é, por natureza, mutável, na medida em que, em cada momento, existem sempre várias alternativas possíveis e diferentes pontos de vista podem emergir. Não obstante, as selecções operadas pela memória denunciam sempre as relações de poder presentes num determinado tecido social, pois, não só quem detém o poder tem a capacidade de activar uma determinada versão da história, e de a consensualizar na esfera pública, como também a sua acção no domínio da memória reflecte uma necessidade de afirmação e fortalecimento da respectiva posição de poder. 
Contudo, o poder de representar não se resume ao produto de uma emanação centralizada, unívoca e unilateral. Existem limites ao exercício deste poder, que está sempre acompanhado de múltiplas e dispersas redes e é ponderado por variadas e conflituais fontes de oposição. À medida que diferentes agendas grupais competem entre si para definir o que a cultura é, ou deve ser, novas versões dos passados colectivos emergem no tecido social, validando e legitimando os interesses representacionais dos grupos que as propõem ou patrocinam. Não há, portanto, versões definitivas dos passados colectivos, pois a natureza situacional das memórias públicas faz com que estejam sempre em fluxo.

No entanto, cada nova versão do passado não deixa de estar informada pelas versões que a antecederam. Estas, embora possam ser, em muitos aspectos, diferentes das ulteriores, fornecem um repertório de possibilidades a partir do qual a recordação colectiva é articulada. É claro que este repertório também não é fixo nem estático, pois as alternativas disponíveis em cada momento gerarão novas possibilidades. Neste processo, novos passados se acumulam, conflituam ou se substituem aos anteriores, num processo criativo e plástico de imaginação e reimaginação do passado em cada presente.

Por outro lado, apesar de a memória se apresentar publicamente de forma unívoca, a permanência de visões alternativas ou dissidentes do passado na esfera privada é evidência de que a memória nunca pode ser totalmente convencionada. Como referem Fentress e Wickam (1992), as pessoas recordam-se de certas vivências específicas porque estas vivências foram significativas para elas, acusando o peso detido pela própria subjectividade na forma como percepcionam o passado. Podem, por isso, contestar ou simplesmente serem indiferentes às versões públicas autorizadas. Podem, também, vir a resgatar da sua própria experiência pessoal novas leituras do passado que actualizem as anteriores, caso o próximo presente forneça as condições contextuais favoráveis a tal revisão da memória.

\section{BIBLIOGRAFIA}

BAL, Mieke, 1999, “Introduction”, em Mieke Bal, Jonathan Crewe e Leo Spitzer (eds.), Acts of Memory: Cultural Recall in the Present. Hanover e Londres, University Press of New England, vii-xvii.

BALIBAR, Etienne, e Immanuel WALLERSTEIN, 1991, Race, Nation, Class: Ambiguous Identities. Londres, Verso. 
CÂMARA MUNICIPAL DE ÍlHAVO, 2002, Ílhavo 2020: Construir uma Visão Partilhada das Opçães e dos Percursos de Desenvolvimento. Documento de Apoio à Preparação do Diagnóstico Prospectivo do Plano Estratégico do Concelho de Ílhavo. Centro de Estudos em Inovação Dinâmicas Empresariais e Territoriais, Departamento de Ambiente e Ordenamento da Universidade de Aveiro, Ílhavo, Câmara Municipal de Ílhavo.

CONnERTON, Paul, 1989, How Societies Remember. Cambridge, Cambridge University Press.

DAYAN, Daniel, 2005, "Mothers, midwives and abortionists: genealogy, obstetrics, audiences and publics”, em Sonia Livingstone (ed.), Audiences and Publics: When Cultural Engagement Matters for the Public Sphere. Bristol e Portland, Intelect Books, 43-76.

DIAS, J. Ferreira, et al., 2001, "A saga do 'fiel amigo': as indústrias portuguesas do bacalhau”, Global Economics and Managment, 1, disponível em <http://bonjorn.sc-eco.univ-nantes. $\mathrm{fr} / \sim$ salmar/EGG2001.pdf > (acesso em 25-02-2003).

DICKS, Bella, 2000, Heritage, Place and Community. Cardiff, University of Wales Press.

FENTRESS, James, e Chris WICKHAM, 1992, Memória Social. Lisboa, Teorema.

FOUCAUlT, Michel, 1977, Language, Counter-Memory, Practice: Selected Essays and Interviews, org. Donald F. Bouchard e Sherry Simon. Nova Iorque, Cornell University Press.

GARRIDO, Álvaro, 2003, O Estado Novo e a Campanha do Bacalhau. Lisboa, Círculo de Leitores.

GRAHAM, Brian, Gregory John ASHWORTH, e J. E. TUNBRIDGE, 2000, A Geography of Heritage: Power, Culture, Economy. Londres, Arnold.

HALBWACHS, Maurice, 1992 [1925], “The social framewoks of memory", em Lewis A. Coser (ed.), On Collective Memory. Chicago, Chicago University Press, 35-189.

HUYSSEN, Andreas, 1995, Twilight Memories: Marking Time in a Culture of Amnesia. Londres e Nova Iorque, Routledge.

JENKS, Chris, 1995, "The centrality of the eye in Western culture", em Chris Jenks (ed.), Visual Culture. Londres e Nova Iorque, Routledge, 1-25.

KOSHAR, Rudy, 2000, From Monuments to Traces: Artifacts of German Memory 1870-1990. Berkeley, University of California Press.

MADAíl, António G. Rocha, 1922, Illiabum: Projecto do Brasão. Ílhavo, Câmara Municipal de Ílhavo.

MARTINS, Luís, 2001, "Os usos da fotografia no Jornal do Pescador e o lançamento das escolas de pesca”, em Álvaro Garrido (coord.), A Pesca do Bacalhau: História e Memória. Lisboa, Editorial Notícias, 181-198.

PERAlTA, Elsa, 2008, A Memória do Mar: Património, Tradição e (Re)imaginação Identitária na Contemporaneidade. Lisboa, ISCSP-UTL.

POMIAN, Krzysztof, 1990, Collectors and Curiosities: Paris and Venice, 1500-1800. Cambridge, Polity Press.

REIS, José, 1993, "Portugal: a heterogeneidade de uma economia semiperiférica", em Boaventura de Sousa Santos (org.), Portugal: Um Retrato Singular. Porto, Edições Afrontamento, 17-56.

SCOTT, James, 1990, Domination and the Arts of Resistance: Hidden Transcripts. New Haven e Londres, Yale University Press.

TERDIMAN, Richard, 1993, Present Past: Modernity and Memory Crisis. Nova Iorque, Cornell University Press.

TURNER, Victor, 1975, "Symbolic studies", Annual Review of Anthropology, 4: 145-161. 
WHELAN, Yvonne, 2005, "Mapping meaning in the cultural landscape", em Gregory John Ashworth e Brian J. Graham (eds.), Senses of Place, Senses of Time. Aldershot, Ashgate, 61-72.

WOLF, Eric R., 2001, Pathways of Power: Building an Anthropology of the Modern World. Berkeley, University of California Press.

"We're all seafarers": an ethnography of the (in)visibilities of power in the social representation of the local past in Ílhavo - Elsa Peralta - Instituto de Ciências Sociais da Universidade de Lisboa, Portugal • elsa.peralta@ics.ul.pt

Taking as an empirical basis the process of construction of a "memory of the sea" in Ílhavo, with particular emphasis on cod fishing, this paper discusses how notions of identity and belonging are constructed by establishing selective images of a past which is activated according to the power agendas of certain groups. In the example analyzed here, the local identity is articulated by a narrative of maritime evocation that reproduces the class identity held by people occupying dominant positions in the hierarchy of the activity now represented. By making "their" past ostensibly visible, these people have made invisible the extreme asymmetries involved in the practice of this activity, thus claiming themselves its main protagonists.

KEYWORDS: memory, identity, class, power, visibility, Ílhavo. 